\title{
DISYUNTIVA DE LAS DISPOSICIONES DE RECLUSIÓN EN LA REFORMA AL ARTÍCULO 18 CONSTITUCIONAL
}

\author{
The Dilemma of the Confinement Provisions of the Reform \\ to Constitutional Article 18
}

\begin{abstract}
Herlinda Enríquez Rubio Hernández ${ }^{1 \cdot}$
Maximiliano Hernández Cuevas ${ }^{* *}$

Sumario:

1. Introducción. 2. Perspectiva práctico-moral. 3. Perspectiva socio-jurídica del problema 4.Conclusiones 5.Bibliografía.
\end{abstract}

Resumen: En el siguiente artículo se presenta una disertación en torno a las disposiciones establecidas en el artículo 18 constitucional, específicamente las que hacen mención de la existencia de centros de reclusión especiales destinados a personas ubicadas dentro de la delincuencia organizada y aquellos internos que requieren de medidas especiales de seguridad. La discusión se realiza desde dos puntos de vista: uno práctico-moral y otro desde la Sociología del derecho. En el primero, se analiza la influencia del desarrollo moral en las producciones legislativas, y en el segundo, la coherencia sistemático-jurídica de las normas referidas, así como los efectos de su aplicación. Haciendo especial énfasis en la paradoja creada por el estado mexicano: haber legislado la aplicación de medidas restrictivas que lastiman severamente a cierto tipo de prisioneros, y que estas normas sean parte de una gran reforma a nuestro sistema penal que, además, en el año 2011, se han revestido de respetuosas de los derechos humanos.

Palabras clave: artículo 18 constitucional, prisiones especiales (máxima seguridad) y medidas especiales.

Abstract: The following article is a dissertation about the established provisions of Article 18 of the Constitution, specifically those that mention the existence of special prisons for people identified within organized crime and those prisoners who require special security measures. The discussion is conducted from two perspectives: one moral-practice and another from Sociology of Law. In the first, the influence of moral development in legislative production is analyzed, and in the second, the systematically-legal coherence of such standards, and the effects of their application. The work emphasizes in particular the paradox created by the Mexican state: having legislated restrictive measures that severely hurt certain types of prisoners, and that these standards are part of a major reform of our penal system that in the year 2011 were cloaked as respectful of human rights.

\footnotetext{
${ }^{*}$ Dra. en Ciencias Políticas y Sociales con orientación en Sociología Jurídica por la UNAM, Profesora investigadora de la Universidad Autónoma de la Ciudad de México. Catedrática y Miembro del Comité de Doctorado del Instituto Nacional de Ciencias Penales.

** Dr. en Ciencias Políticas y Sociales con orientación en Sociología Jurídica por la UNAM, Profesor investigador de la Universidad Autónoma de la Ciudad de México. Miembro del Sistema Nacional de Investigadores-1 y Catedrático del Instituto Nacional de Ciencias Penales.
} 
Keywords: Article 18 of the Constitution, special prisons (maximum security) and special measures.

\section{INTRODUCCIÓN}

Hacer referencia al ejercicio pleno de las libertades subjetivas y, en otro sentido, a la necesidad de restringirlas jurídicamente en nombre del interés colectivo, es uno de los temas básicos de controversia filosófico-teorética en torno al derecho contemporáneo, el cual se funda sobre la idea de respetar y proteger los derechos humanos.

Puede afirmarse que este es uno de los puntos de mayor tensión en los actuales estados democráticos. Problemática que sólo con el auxilio de la filosofía y la teoría del derecho por un lado, y las ciencias sociales y políticas por el otro, es posible resolver plausiblemente. ${ }^{2}$

Por ello la convergencia de estas disciplinas, en la medida de lo posible, estará viva a lo largo del presente artículo, cuyo propósito es revelar que el estado mexicano mantiene en el artículo 18 constitucional dos posiciones antagónicas: por un lado, que se ordena el respeto a los derechos humanos como base para organizar el sistema penitenciario y, por el otro, que también se prescribe la aplicación de medidas restrictivas para cierto tipo de prisioneros que los sujetan a circunstancias opuestas a la salvaguarda de su integridad. ${ }^{3}$

$\mathrm{Al}$ respecto, cuando nos preguntamos acerca de las repercusiones del encierro en los seres humanos, es pertinente observar las circunstancias de vida dentro de esa realidad y detenernos en el análisis de las diversas etapas que se viven a lo largo del internamiento, poniendo especial énfasis en los períodos que resultan insoportables de manera prolongada. Y que ante tales particularidades, el daño a los reclusos resulta inminente y generalizado.

Este sufrimiento lo podemos identificar palpablemente en las personas que tienen la necesidad de purgar una sentencia de por vida dentro de establecimientos de reclusión especial, conocidos en México como de máxima seguridad. El trato de que los prisioneros son objeto da cuenta del abuso de poder legalizado, mismo que se traduce en una constante violación a sus derechos fundamentales. ${ }^{4}$

\section{PERSPECTIVA PRÁCTICO-MORAL}

$\mathrm{Al}$ abordar el tema que nos inquieta se precisa dirigir nuestra atención hacia la vida prácti$\mathrm{ca}$, dentro de la que interactuamos y procuramos dar solución a los conflictos propios de la convivencia en sociedad. En ella, la diversidad de acciones llevadas a cabo entre individuos y

\footnotetext{
2 Respecto a los avances en la solución a la contradicción existente entre la autonomía privada y el interés público véase HABERMAS, Jürgen, Facticidad y validez. Sobre el derecho y el Estado democrático de derecho en términos de teoría del discurso. $4^{\text {a }}$ edición, Trotta, Madrid, 2005. Particularmente se sugiere revisar el capítulo IX.

3 El artículo 18 de la Constitución Política de los Estados Unidos Mexicanos, establece: “El sistema penitenciario se organizará sobre la base del respeto a los derechos humanos (...)”.

4 Se alude específicamente a lo estipulado en el último párrafo del artículo 18 constitucional, relativo a los centros especiales y las medidas especiales de seguridad destinadas a prisioneros pertenecientes a la delincuencia organizada, y respecto de otros internos que las requieran.
} 
grupos es coordinada con base en las valoraciones que culturalmente hacemos sobre nuestro entorno vital (natural, social y simbólico).

Y en esto último cobra especial importancia la moral, a la que podemos entender como el entramado de hábitos y costumbres grupalmente convenido que, junto con las respectivas normas que de su práctica se desprenden, da sentido y regula, en primera instancia, la interacción humana. ${ }^{5}$ Cabe entonces, en función de lo anterior, considerar que la moral produce - y a su vez es resultado- de los valores que forman y dotan de significado a una cultura y vida social determinadas. Acerca de ello, es necesario hacer algunas precisiones:

$1^{\text {a }}$ La moral cambia en función del lugar y el tiempo en que surge y se realiza.

$2^{\mathrm{a}}$ Los cambios que presenta dependen del grado de descentración alcanzado por los individuos y grupos que la practican tanto en su trato entre ellos mismos, como respecto a quienes les resultan ajenos (esto es lo que se conoce como desarrollo moral ${ }^{6}$ ).

$3^{\text {a }}$ Lo anterior significa que las valoraciones morales dependen del grado de conciencia que los individuos y grupos tienen sobre cuestiones pertenecientes a sus diferentes contextos de realidad (de carácter objetivo, social y subjetivo). Así, puede decirse que en la medida en que un individuo y la cultura en la cual vive están más descentrados, los valores morales y los supuestos orientados por éstos son fruto de una moral más reflexiva.

$4^{\text {a }}$ En una moral con mayor desarrollo los principios y valores tienden a ser universales, de manera que la relación entre los individuos y grupos se inclina al reconocimiento mutuo alejado de las actitudes excluyentes y la discriminación.

Con estas observaciones podemos comprender por qué en una sociedad cuya moral es más avanzada, el interés del individuo que reivindica el trato justo e igualitario para cada uno puede anteponerse al bien común cuando en nombre de éste se lesiona la integridad de las personas, por ejemplo, con la aplicación de estrategias de seguridad pública o de seguridad nacional.

En tal escenario, con el argumento de que se precisa neutralizar la amenaza que representa la delincuencia organizada, el estado mexicano ha tomado medidas extremas que afectan discriminatoriamente a los sentenciados a pena de prisión por esta clase de delitos, sin considerar que en las sociedades actuales ningún acto criminal es lo suficientemente grave

5 Decimos que en primera instancia porque las normas morales son la base constituyente de la convivencia social, es decir, que de ellas derivan los demás sistemas normativos —incluidos los de carácter jurídico- que emergen y se diversifican conforme una sociedad se va volviendo más compleja (lo cual no implica, como se sabe, que el derecho tenga sólo como única fuente a las normas morales).

6 Propuesta desarrollada por el filósofo Lorenz Kolberg. La idea nuclear es que el individuo de modo natural y por supervivencia nace egocéntrico, y conforme se desarrolla en convivencia con los demás va reconociendo a éstos como sus álter ego y logra verse a sí mismo como parte de un nosotros (en lugar de ser el centro), hasta llegar a constituirse como un individuo que actúa bajo principios universales de carácter ético. Sobre dicha orientación, Habermas ha propuesto que las sociedades también se desarrollan moralmente, de modo que en su devenir histórico éstas adquieren una concepción del mundo menos socio-céntrica, o etno-céntrica, para dar paso a una integración planetaria de la sociedad. Al respecto véase HABERMAS, Jürgen, Conciencia moral y acción comunicativa. Trotta, Madrid, 2008, pp. 121-194; y HABERMAS, J. La reconstrucción del materialismo histórico. Taurus, México, 1992, pp.68-69. 
para que moralmente pueda justificarse cualquier acción punitiva especial que lesione la condición humana de los condenados. ${ }^{7}$

Y por supuesto, el intento de su justificación a nivel jurídico entra en crisis de legitimidad debido a la estructuración y práctica del derecho contemporáneo, en el que los argumentos para justificar una acción o norma también se emiten con pretensión de rectitud normativa; y esta última, se basa en principios universales --en gran parte fruto de la razón práctica-que han derivado en uno de los principales logros del actual desarrollo moral: los derechos humanos. $^{8}$

\section{PERSPECTIVA SOCIO-JURÍdiCA DEL PROBLEMA}

En consonancia con lo anterior, penetraremos ahora en el tema de las personas privadas de su libertad que cumplen una sentencia por un largo periodo o por el resto de sus días, sea en un centro de readaptación de máxima seguridad o en alguno convencional, bajo las medidas especiales que la autoridad en turno haya decidido aplicarle.

A fin de exponer de forma concisa los efectos que produce el encierro en la prisión, es necesario acudir a trabajos empíricos de probada rigurosidad científica; uno que resulta emblemático es el de Erving Goffman, ${ }^{9}$ quien estudió a las instituciones que poseen la característica de absorber en grado mayor el tiempo y el interés de sus miembros, creándoles un mundo propio; es decir: lugares con absorbencia totalizadora, simbolizada por obstáculos ${ }^{10}$ que se oponen a la interacción social con el exterior, y al éxodo de quienes se encuentran en calidad de internos. A estos sitios los denominó: Instituciones Totales, mismos que clasificó y dentro de los cuales se identifica a la prisión. ${ }^{11}$

Es, precisamente por su peculiaridad totalitaria, que en esta clase de establecimientos la vida diaria es aflictiva, pues desde que se ingresa en ellos, en calidad de interno, la degradación y la mortificación del yo es sistemática, puesto que esto es una finalidad implícita,

7 En el terreno moral las justificaciones se realizan con pretensión de corrección, es decir, para determinar - por vía de la discusión argumentativa - la rectitud de las acciones sobre las cuales se discute. De tal modo, cabe observar que los conflictos tienden a ser resueltos racionalmente, más que por vía de la tradición irreflexiva. El desarrollo moral de una sociedad se refleja en sus instituciones y el grado en que por medio de éstas se facilita que los individuos puedan reconocerse con derechos y con la facultad de hacerlos valer, especialmente por ellos mismos, a través de la generación de escenarios de expresión y disputa racionales en torno a temáticas conflictivas.

8 Vale afirmar que ninguna norma es legítima cuando es contraria al sistema de los derechos humanos Sobre el tema, véase, HABERMAS, J., Facticidad y validez...pp. 160 y ss.; FERRAJOLI, L., Derecho y razón...pp. 868 y ss.; y FERRAJOLI, Luigi, Epistemología jurídica y garantismo. Fontamara, México, 2004, pp. 123 y 133 134. Con respecto a las bases de la argumentación jurídica, véase ALEXY, Robert, El concepto y validez del derecho, Gedisa, Barcelona, España, 1994, pp. 37-41 y 87-122; ATIENZA, Manuel, El derecho como argumentación. Fontamara, México, 2012, pp. 67-72 y 120-131; ATIENZA, Manuel, Las razones del derecho. Teorías de la argumentación jurídica, Universidad Nacional Autónoma de México, Instituto de Investigaciones Jurídicas, México, 2011, pp. 190-219.

9 GOFFMAN, E., Internados, Amorrortu, Buenos Aires, 200o, pp. 18-19

${ }^{10}$ Ibídem. (...) que suelen adquirir forma material: puertas cerradas, altos muros, alambre de púas, acantilados, ríos, bosques o pantanos (...)

${ }^{11}$ Ibídem. (...) un tercer tipo de institución total, organizado para proteger a la comunidad contra quienes constituyen intencionalmente un peligro para ella, no se propone como finalidad inmediata el bienestar de los reclusos: pertenecen a este tipo las cárceles, los presidios, los campos de trabajo y de concentración (...) 
de carácter consustancial, inherente a este tipo de instituciones12 (en las cuales se percibe nítidamente cómo el personal que labora en su interior busca consumarla cabalmente, toda vez que las funciones declaradas u oficiales de la prisión están muy lejos de cumplirse) $)^{13}$

Aunado a lo anterior, conviene resaltar un aspecto de la vida de los seres humanos que se lesiona de manera contundente en la cárcel: es el correspondiente a la realización de aquellos actos que, en la sociedad civil exterior, cumplen la función de demostrarle a su ejecutor que tiene cierto dominio sobre su mundo, es decir, que es una persona dotada de la autodeterminación, la autonomía y la libertad de acción propias de un adulto. ${ }^{14}$ Lesión que es reiterada de manera constante, tan sólo por la reglamentación propia de dichas instituciones, ${ }^{15} \mathrm{y}$ que se va a traducir en un sentimiento de profunda desgracia e impotencia experimentado por el interno. De tal manera, la libertad de un sujeto para pensar, expresarse, moverse, de elegir entre diversas alternativas que la vida le ofrece... en suma, su libertad de decidir y conducirse en torno a su propia existencia dentro de la prisión, se ve seriamente circunscrita y disminuida por el régimen totalitario que sojuzga su singularidad. ${ }^{16}$

El grado en que se presentan tales reacciones, variará en consideración a múltiples factores, entre ellos: la situación biográfica de cada interno, su acervo de conocimiento a mano, su calidad delincuencial y, primordialmente, el tiempo que le tomará compurgar su sentencia. Es frecuente escucharlos decir, en especial dentro de una penitenciaría (donde, generalmente, quienes se encuentran ahí recluidos poseen sentencias mayores a los treinta años, y han agotado todas las instancias posibles a favor de su defensa), que preferirían morir a vivir en un encierro de por vida. Es más, no es extraño escuchar historias de prisioneros que han atentado contra su propia vida, ante una negativa judicial a lo largo de su proceso.

Ahora bien, si a todo esto se añaden las mencionadas medidas especiales, incorporadas a la Constitución mediante la reforma penal de junio de 2008, las repercusiones se agudizan al grado de que los reclusos llegan a desear su propia muerte, no sólo por saberse en encierro de por vida, sino porque las condiciones a las que son sometidos se tornan insoportables. Es sabido que de por sí, en las prisiones de máxima seguridad, algunos testimonios muestran que los detenidos prefieren la muerte antes que aceptarse como seres sin derechos, o sin la garantía de que se respetarán los derechos que cualquier otro interno tendría, por la sola razón de ser un recluso. ${ }^{17}$

En la realidad social, la calidad de especiales que poseen las medidas aludidas, las hace aún más enigmáticas, ya que "especial" significa: "Singular o particular que se diferencia

\footnotetext{
${ }^{12}$ ENRÍQUEZ RUBIO, H., El pluralismo jurídico intracarcelario. Porrúa, México, 20o8. Véase, Capítulo II, pp. 29-81.

${ }^{13}$ Cfr. HERnÁNDEZ CUEVAS, M., Trabajo y derecho en la prisión. Porrúa, México, 2011. Véase, Conclusiones, pp. 171-176.

14 GOFFMAN, Op. Cit., p.53

${ }^{15}$ ENRÍQUEZ RUBIO..., Op. Cit., Sea ésta la oficial o la extraoficial. Véase, Los códigos de castigos de los sistemas normativos Intracarcelarios, pp.183-239.

${ }^{16}$ HERNÁNDEZ CUEVAS... Op. Cit., p. 162.

${ }^{17}$ Un ejemplo revelador es un caso de ajusticiamiento en una penitenciaría del Estado de Utah, Estados Unidos de América: el condenado a la pena de muerte fue Gary Glimore, quien pasó casi toda su vida, a partir de su juventud temprana, entrando y saliendo de prisión. Finalmente, fue detenido en una prisión de máxima seguridad, y, no obstante que hubo mucho movimiento de su defensa y de organismos civiles a favor de que se le conmutara la pena de muerte por la de cadena perpetua, el condenado insistía en que se le respetase su deseo de "morir con dignidad"; esto, debido a que no soportaba ya la idea de permanecer en las condiciones a que fue sometido a vivir en un régimen de máxima seguridad. Su resistencia a seguir con vida la manifestó en distintos escritos y entrevistas. A continuación, estas son algunas expresiones reveladoras de lo que sentía
} 
de lo común, de lo general. Muy adecuado o propio para algún efecto. Y que está destinado para un fin esporádico". ${ }^{18}$ Así, ante la ambigüedad e indefinición que el vocablo "especial" conlleva, hacemos hincapié en que su uso en un texto legal propicia una grave afectación al ámbito social, entre otros, de aquellos internos que son o pudieran ser identificados como parte de la delincuencia organizada, así como de todo aquel prisionero que a discreción de la autoridad encargada lo requiriese; toda vez que el ordenamiento constitucional referido contempla lo siguiente:

La imposibilidad de ubicar a este tipo de internos en centros penitenciarios lo más cercanos a su domicilio, toda vez que, para ellos se destinarán centros especiales tanto para su reclusión preventiva como para la ejecución de sus sentencias.

La restricción de las comunicaciones de los inculpados y sentenciados con terceros dejando sólo a salvo el acceso a su defensor.

La imposición de una vigilancia especial a quienes se encuentren internos en los centros especiales, sin especificar exactamente en qué consistirá.

Frente a tales excepciones, la calidad de vida del recluso especial es diversa a la de cualquier otro, esto es: su esfera afectivo-social resulta dañada en extremo, ya que la impotencia para atender sus necesidades existenciales ${ }^{19}$ así lo prueba.

En un ejercicio prospectivo, los individuos sometidos a un régimen de este tipo difícilmente podrán mantener la estabilidad emocional, puesto que la des-estructuración de su personalidad menguará sus aptitudes para actuar en la vida. El tratamiento oficial a estos internos, de manera latente, no tendrá como propósito velar por la declarada reinserción social de los mismos -cuando ello proceda-, como lo prescribe nuestra carta magna, sino que, de facto, se enfocará a un quehacer cuyo objetivo sólo será el deterioro. ${ }^{20}$

Ante esto, se precisa discurrir en torno a los derechos humanos garantizados constitucionalmente y que, por su carácter de fundamentales, no pueden ser restringibles ipso iure, in-

y pedía, y sobre lo cual, incluso, llegó a tener apoyo patente de algunos familiares (Véase, MAILER, Norman, La canción del verdugo. Anagrama, Barcelona, 1995 -Obra publicada en inglés, por primera vez, en 1979): "Si me conmutas la sentencia -dijo Gary-, no serás tú quien haya de vivir en prisión. ¿¿Sabes la fuerza que se necesita para continuar año tras año en un lugar como éste? (p. 508); "En mi última carta te decía que me fusilarán el 17 de enero. Esas cuatro balas del calibre 30 van a liberarme (...)" (p. 486); "El padre Meersman estaba convencido de haberse acercado a Gary (...) por haber expresado su deseo de morir con dignidad, cosa que le impresionó (...)” (p. 487); Finalmente: “Carta abierta de Gary Gilmore a todos aquellos que siguen oponiéndose, por uno u otro medio, a una ejecución legal que me dé la muerte, en particular la ACLU y la NAACP: Os invito a desentenderos de una vez por todas de mí, de mi vida y de mi muerte. No os conciernen (...)" (p. 483).

${ }^{18}$ DRAE, Diccionario de la Real Academia Española, 22. ${ }^{a}$ edición.

${ }^{19}$ Véase, HERNÁNDEZ CUEVAS... Op. Cit. Capítulo 6, necesidades de raigambre, de unidad propia de la existencia del ser humano, de efectividad, de estimulación y de excitación, pp.152-158.

${ }^{20}$ En 2003 la Oficina del Alto Comisionado de las Naciones Unidas en México publicó un diagnóstico sobre la situación de los derechos humanos en nuestro país, en el que sobre las prisiones de máxima seguridad se destacó lo siguiente: ${ }^{*}$ Condiciones degradantes del régimen de visita familiar: - Espacios reducidos - Presencia cercana y permanente de vigilantes -Filmación (video) de visita íntima ${ }^{*}$ Revisión a visitantes: -Desvestirse por completo, incluyendo niños y ancianos. ${ }^{*}$ Excesos en la aplicación de la segregación: -Sin motivación legal -Por tiempo indeterminado -Por faltas mínimas -Violando el derecho de audiencia -En condiciones infrahumanas (sin cama, sin instalaciones sanitarias, sin luz ni ventilación natural) -En las áreas de tratamiento médico *Violación de la garantía de inviolabilidad de la correspondencia. ${ }^{*}$ Uso de la psiquiatría, la medicina 
cluso al aplicarse la pena de prisión; ${ }^{21}$ éstos deben ser protegidos, no violentados por ningún organismo del poder público. No obstante, con la reforma penal mencionada, el legislador engendró una seria contradicción tanto en la misma carta magna, como en su relación con el sistema internacional de los derechos humanos del cual nuestro régimen jurídico forma parte. ${ }^{22}$ La incompatibilidad referida está ubicada en los párrafos penúltimo y último del artículo 18:

(...) Los sentenciados, en los casos y condiciones que establezca la ley, podrán compurgar sus penas en los centros penitenciarios más cercanos a su domicilio, a fin de propiciar su reintegración a la comunidad como forma de reinserción social. Esta disposición no aplicará en caso de delincuencia organizada y respecto a otros internos que requieran medidas especiales de seguridad.

Para la reclusión preventiva y la ejecución de sentencias en materia de delincuencia organizada se destinarán centros especiales. Las autoridades competentes podrán restringir las comunicaciones de los inculpados y sentenciados por delincuencia organizada con terceros, salvo el acceso a su defensor, e imponer medidas de vigilancia especial a quienes se encuentren internos en estos establecimientos. Lo anterior podrá aplicarse a otros internos que requieran medidas especiales de seguridad, en términos de la ley. ${ }^{23}$

Si sometemos a un análisis sistemático el contenido de estos párrafos, podemos observar lo siguiente:

1er. ARGUMENTO. En el penúltimo de los párrafos se vulnera el principio de igualdad, que es cimiento del sentido de justicia, principio que fundamenta nuestro sistema jurídico

y las ciencias de la conducta como formas de control: -Utilización de camisas de fuerza como forma agravada de segregación -Administración obligatoria de psicofármacos -Tratamiento psiquiátrico y psicológico obli-


de defensa: -Impedir que el defensor acuda con documentos de trabajo -Prohibición de entrevista con el defensor a los internos que se encuentren en el área de tratamientos especiales -Restricción a la comunicación telefónica con los defensores (diez minutos al día) -Intervención en la comunicación con los defensores (las entrevistas son grabadas) -Imposibilidad de acceder a la legislación vigente para acceder el derecho a defenderse por sí mismo -Revisiones degradantes de los defensores -Invasión de la privacidad en la comunicación -Dilaciones en el acceso a los defensores -Prohibiciones para reunirse simultáneamente con dos defensores o con peritos -Prohibición de asistir a audiencias fuera del CEFERESO (Centro Federal de Readaptación Social) ${ }^{*}$ Obstrucción del derecho a formular peticiones legítimas a la autoridad y de presentar quejas: -Toma de represalias contra internos que se quejan -Falta de organismos fiscalizadores -Obstrucción a organizaciones civiles y públicas defensoras de derechos humanos *Trato cruel por actos de vigilancia excesiva y tortura: - Interrupción sistemática del sueño de los internos -Luz permanente en las celdas -Vigilancia permanente mediante cámaras de televisión -Presencia ininterrumpida de un custodio -Prohibición de toda comunicación personal entre los internos -Revisiones excesivas e irracionales -Casos de tortura al aplicarse sanciones de aislamiento por periodos prolongados -El internamiento de mujeres en estos centros diseñados para varones y ocupados por éstos en forma casi absoluta. OFICINA DEL ALTO COMISIONADO DE LAS NACIONES UNIDAS PARA LOS DERECHOS HUMANOS EN MÉXICO, Diagnóstico sobre la situación de los derechos humanos en México. Mundi-prensa, S. A., México, 2003, pp. 22-23.

${ }^{21}$ Con la sanción privativa de libertad sólo deben restringirse el derecho a la libertad de tránsito y los derechos políticos.

${ }^{22}$ Sistema que es la base de todo Estado de derecho contemporáneo.

${ }^{23}$ Las cursivas han sido puestas por los autores. 
y todo el sistema internacional de los derechos humanos. ${ }^{24} \mathrm{El}$ hacer diferenciaciones entre los prisioneros por motivos de seguridad, pone de manifiesto que se está dando prioridad constitucional a ésta en detrimento de uno de los puntos de apoyo centrales del sistema de los derechos.

En efecto, dicha disposición representa una seria interrupción de la COHERENCIA SISTÉMICA tanto en nuestro sistema jurídico como en el internacional, puesto que el reconocimiento de sujetos especiales que requieren medidas especiales es contrario a una porción esencial del artículo primero de nuestra constitución, referida en él tácita y explícitamente, a saber: el principio de igualdad. ${ }^{25}$ Estamos ante lo que en la Teoría del Derecho se denomina derecho ilegitimo, es decir, la norma en cuestionamiento carece de validez aunque haya sido dotada de legalidad. ${ }^{26}$

$2^{\circ}$ ARGUMENTO. Otro principio que se ve afectado con la redacción de los párrafos analizados es el de integridad: apelar a la necesidad de preservar la seguridad pública, o aun la nacional, como sustento de la normatividad sobre delincuencia organizada contraviene el contenido de dicho principio, expresado abiertamente en instrumentos internacionales de derechos humanos; ${ }^{27}$ mismo que también puede ser ubicado con cierta facilidad, aunque carezca de explicitud, en diversos artículos del primer capítulo de nuestra constitución.

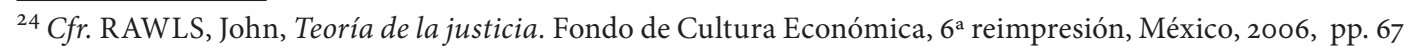
y ss.; igualmente, HABERMAS, J. Facticidad y validez..., pp. 502-512.

${ }^{25}$ COMENTARIO. En primer lugar, con la expresión: "Está prohibida la esclavitud..." se protege el principio o derecho a la libertad, pero también se resguarda el principio de igualdad al dotar a todas las personas de un mismo estatus legal (en el sentido de que nadie puede ser propietario de otro, y por ende desigual). En segundo lugar: "Queda prohibida toda discriminación motivada por origen étnico o nacional, el género, la edad, las discapacidades, la condición social, las condiciones de salud, la religión, las opiniones, las preferencias sexuales, el estado civil o cualquier otra que atente contra la dignidad humana y tenga por objeto anular o menoscabar los derechos y libertades de las personas". Con la prohibición de discriminar a cualquier individuo, en las diversas facetas propias de la condición humana, se protege (garantiza) el respeto al principio (derecho) de igualdad; y al respecto, es pertinente observar que esto también atañe a los reclusos en razón de su humanidad, la cual está por encima de cualquier restricción jurídica que la violente de modo indignante.

${ }^{26}$ Como puede notarse, en teoría del derecho, legalidad y legitimidad no son conceptos equivalentes. El primero carece de sustento sin el segundo, que, a su vez, adquiere fuerza no sólo mediante la aceptación mayoritaria de la ciudadanía, sino sólo cuando tal aceptación está fundamentada jurídica, política y filosóficamente, en la discusión y argumentación racional. Al respecto de la validez normativa, la legitimidad, y los principios. Véase, por ejemplo, FERRAJOLI, L. Derecho y razón...pp. 868 y ss.; HABERMAS, J., Facticidad y validez..., p. 164; ATIENZA, Manuel y RUIZ M., Juan, Las normas de mandato: principios y reglas, en PLATTS, Mark (comp.), Conceptos éticos fundamentales, UNAM, Instituto de Investigaciones Filosóficas, México, 2006, pp.401-433.

${ }^{27}$ Véase, Convención Americana sobre Derechos Humanos, Artículo 5: "Derecho a la integridad personal. 1. Toda persona tiene derecho a que se respete su integridad física, psíquica y moral (...)". Por su parte, conviene advertir que no obstante en este mismo documento (en el Artículo 15. Derecho de reunión), se prescribe que "en interés de la seguridad nacional, de la seguridad o del orden públicos", el derecho de reunión puede estar sujeto "a las restricciones previstas por la ley", esto sólo se observa, precisamente, para el caso de la libertad de reunión. Pero, aun en este caso, conforme a la estructura del sistema de los derechos humanos, no puede atentarse contra derechos como la integridad personal. Aquí no hay conflicto de derechos, pues el de la integridad, como fundamental, prevalece sobre cualquier otro que al intentarse hacer valer lo ponga en grave riesgo o definitivamente lo afecte de forma seria. NOTA: México se adhirió a la Convención el 24 de marzo de 1981, y su texto fue publicado en el Diario Oficial de la Federación el 7 de mayo de ese mismo año. Cfr. RODRÍGUEZ Y RODRÍGUEZ, Jesús, Instrumentos Internacionales sobre Derechos Humanos Comentados, Comisión Nacional de los Derechos Humanos, México, 1996, p. 176. 
Es importante destacar que los motivos de seguridad nacional o de seguridad pública, generalmente justificados con la noción del interés común, históricamente han servido para cometer terribles atentados a los derechos subjetivos, en particular al de la integridad física, psíquica y moral; cuando sucede, también se perturba de modo grave el sentimiento o percepción de seguridad de las personas.

3er ARGUMENTO. En lo correspondiente al último párrafo del artículo, el restringir las comunicaciones e imponer medidas de vigilancia especial, además de ser un precepto opuesto al principio de igualdad, que de suyo previene el trato segregativo o excluyente altamente violento para la condición humana-, asimismo atenta contra el principio de integridad al obstaculizar la satisfacción de necesidades básicas del recluso en lo que atañe, por una parte, a la convivencia con los demás, y por otra, a contar con privacidad. ${ }^{28}$ Todo esto en contra de su salud psíquica y, por ende, de lo que al respecto prescribe y garantiza la misma Constitución en su artículo 4 párrafo cuarto: “Toda persona tiene derecho a un medio ambiente adecuado para su desarrollo y bienestar.”

$4^{\circ}$ ARGUMENTO. Respecto de lo ordenado en las dos últimas líneas del artículo: "Lo anterior podrá aplicarse a otros internos que requieran medidas especiales de seguridad, en términos de la ley." Basta decir que ningún término de ley derivado de la norma aquí cuestionada, puede ser legítimo al provenir de ésta; en razón de ello, también resulta jurídicamente inválido aplicar las medidas especiales a los internos aludidos.

Con los razonamientos expuestos se pone en evidencia el autoritarismo de la norma cuestionada. Y, con relación a esto, la incontrovertible necesidad de tener muy claro que toda legislación indiferente a los derechos fundamentales ofende a la igualdad, a la integridad, y por lo tanto a la dignidad de las personas. Dicho de otra manera: desde la perspectiva actual de la Teoría del Derecho toda normatividad que quebrante derechos fundamentales deja de pertenecer al Sistema de los Derechos, que es sustento del derecho internacional contemporáneo al igual que de los actuales estados de derecho, entre los cuales se encuentra el Estado Mexicano. En síntesis, cualquier matiz de encubrimiento regula autoritarismo y por ende constituye derecho ilegítimo, ${ }^{29}$ puesto que es improcedente tratar a alguien como enemigo antes que como humano.

Lo observado hasta ahora bastaría para demostrar que las medidas especiales aquí debatidas son contrarias al derecho legítimo; sin embargo, al examinar otros documentos normativos internacionales, como es el caso de la "Convención Contra la Tortura y Otros Tratos o Penas Crueles, Inhumanas o Degradantes", ${ }^{30}$ podemos destacar, aún más, la inconsistencia sistémica de aquéllas:

Al revisar el artículo $1^{\circ}$ de la Convención, donde es definida la tortura se previene a los Estados firmantes de no infligir “(...) intencionalmente a una persona dolores o sufrimien-

\footnotetext{
${ }^{28}$ Ello, además de otras circunstancias intensamente nocivas del ambiente de esos centros de reclusión descritas anteriormente.

${ }^{29}$ En el mismo tenor, la legitimidad y la validez incluso aquellos tratados o convenciones que con motivo del combate a la delincuencia organizada contravengan el sistema internacional de los derechos humanos, está en entredicho.

${ }^{30}$ Ratificada por el Estado mexicano el 23 de enero de 1986, y se publicó en el Diario Oficial de la Federación el 6 de marzo de ese mismo año. Cfr. RODRÍGUEZ Y RODRÍGUEZ, Jesús, Instrumentos Internacionales sobre Derechos Humanos Comentados. Comisión Nacional de los Derechos Humanos, México, 1996, p. 94.
} 
tos graves, ya sean físicos o mentales, con el fin (...) de castigarla por un acto que haya cometido, o se sospeche que (ha) cometido(...)"; y al final de este párrafo, especifica, empero, que no serán considerados tortura "(...) los dolores o sufrimientos que sean consecuencia únicamente de sanciones legítimas, ${ }^{31}$ o que sean inherentes o incidentales a éstas".

Al respecto cabe advertir, en primer lugar, que dicho instrumento, firmado y ratificado por el Estado Mexicano, forma parte de nuestra legislación y protege al individuo ${ }^{32}$ de tratos degradantes y sufrimientos que pudieran afectar su integridad. Y, en segundo término, que aun cuando los prisioneros -incluidos los de la delincuencia organizada- estén sujetos a pena de privación de la libertad, es improcedente que en dicha sanción, en sí misma legal y legítima, se pretenda contemplar a las medidas especiales de seguridad y vigilancia, que por su propiedad antinómica resultan carentes de legitimidad. Una ley no es legítima y por tanto válida si rebasa principios de justicia y principios generales del derecho. ${ }^{33}$

\section{CONCLUSIONES}

Bajo argumentos que intentan contrarrestar la amenaza que representa la delincuencia organizada, en el artículo 18 constitucional se han instaurado medidas especiales que afectan discriminatoriamente a los sentenciados a pena de prisión por esta clase de delitos, sin tomar en cuenta que ningún acto criminal es lo suficientemente grave para que moralmente puedan justificarse acciones punitivas por parte del estado que lesionen la condición humana de los condenados.

Las medidas especiales de seguridad, constituyen la legalización de prácticas denunciadas como nocivas e ilegítimas en materia del respeto a los derechos fundamentales de los detenidos en centros de máxima seguridad, o en cualquier reclusorio en donde se aplican a internos que las requieran.

La congruencia entre la inscripción del estado mexicano al Sistema Internacional de los Derechos Humanos y su producción legislativa nacional, exige eliminar del texto de la Constitución el establecimiento de medidas que discriminen a personas que pertenezcan o no a la delincuencia organizada. La selección excluyente contraviene al derecho contemporáneo.

5. BIBLIOGRAFÍA

ALEXY, Robert, El concepto y validez del derecho, Gedisa, Barcelona, España, 1994.

ATIENZA, Manuel y RUIZ M., Juan, Las normas de mandato: principios y reglas, en PLATTS, Mark (comp.), Conceptos éticos fundamentales. UNAM, Instituto de Investigaciones Filosóficas, México, 2006.

\footnotetext{
${ }^{31}$ Las cursivas han sido puestas por los autores del presente estudio.

${ }^{32}$ Con mayor fuerza aun, a partir de la reciente reforma en materia de derechos humanos, que ha colocado en el Art. $1^{\circ}$ de la Constitución lo siguiente: "En los Estados Unidos Mexicanos todas las personas gozarán de los derechos humanos reconocidos en esta Constitución y en los tratados internacionales de los que el Estado Mexicano sea parte (...)".

${ }^{33}$ Véase, HABERMAS, J., Facticidad y validez..., pp. 172-177, 326-334. 
, El derecho como argumentación, Fontamara, México, 2012.

, Las razones del derecho. Teorías de la argumentación jurídica, Universidad Nacional Autónoma de México, Instituto de Investigaciones Jurídicas, México, 2011.

ENRÍQUEZ RUBIO H., Herlinda, El pluralismo jurídico intracarcelario, Porrúa, México, 2008.

FERRAJOLI, Luigi, Derecho y razón. Teoría del garantismo penal, 9a ed., Trotta, Madrid, 2009.

, Epistemología jurídica y garantismo, Fontamara, México, 2004.

GOFFMAN, Erving, Internados. Amorrortu, Buenos Aires, 2000.

HABERMAS, Jürgen, Conciencia moral y acción comunicativa. Trotta, Madrid, 2008.

, Facticidad y validez. Sobre el derecho y el Estado democrático de derecho en términos de teoría del discurso. $4^{\mathrm{a}}$ ed., Trotta, Madrid, 2005.

, La reconstrucción del materialismo histórico, Taurus, México, 1992.

, Teoría de la acción comunicativa, Taurus, México, 2002, Vol. I.

HERNÁNDEZ CUEVAS, Maximiliano, Trabajo y derecho en la prisión. Porrúa, México, 2011.

MAILER, Norman, La canción del verdugo, Anagrama, Barcelona, 1995.

OFICINA DEL ALTO COMISIONADO DE LAS NACIONES UNIDAS PARA LOS DERECHOS HUMANOS EN MÉXICO, Diagnóstico sobre la situación de los derechos humanos en México. Mundi-prensa, S. A., México, 2003.

RAWLS, John, Teoría de la justicia, Fondo de Cultura Económica, México, 2006.

DICCIONARIOS

DRAE, Diccionario de la Real Academia Española, 22. a edición.

\section{DOCUMENTOS NORMATIVOS}

Capítulo I de la Constitución Política de los Estados Unidos Mexicanos. Minuta del proyecto de decreto aprobado por el Senado de la República el 8 de Marzo de 2011.

Convención Americana sobre Derechos Humanos. Aprobada en San José, Costa Rica, el 20 de noviembre de 1969. En RODRÍGUEZ Y RODRÍGUEZ, Jesús, Instrumentos Internacionales sobre Derechos Humanos Comentados, México, Comisión Nacional de los Derechos Humanos, 1996.

Convención Contra la Tortura y Otros Tratos o Penas Crueles, Inhumanas o Degradantes. Aprobada en Nueva York, el 10 de diciembre de 1984. En RODRÍGUEZ Y RODRÍ- 
Herlinda Enríquez Rubio Hernández

Maximiliano Hernández Cuevas

GUEZ, Jesús, Instrumentos Internacionales sobre Derechos Humanos Comentados, México, Comisión Nacional de los Derechos Humanos, 1996 